\title{
Location of Scoliosis and Postural Reactions Among Girls Aged 7-18 Years
}

\author{
Jacek Wilczyński ${ }^{1}$, Natalia Habik ${ }^{2}$, Sylwia Janecka² ${ }^{2}$ Przemysław Karolak ${ }^{2}$, Alicja Śliwa ${ }^{2}$ \& Igor Wilczyński ${ }^{3}$ \\ ${ }^{1}$ Head of Posturology Department, Hearing and Balance Rehabilitation, Institute of Physiotherapy, Faculty of \\ Medicine and Health Sciences, Jan Kochanowski University in Kielce, Poland \\ ${ }^{2}$ Faculty of Medicine and Health Sciences, Jan Kochanowski University in Kielce, Poland \\ ${ }^{3}$ Outpatient Rehabilitation Centre for Children, State Health Care Center in Starachowice, Poland \\ Correspondence: Assoc. Prof. UJK Jacek Wilczyński, Ph.D., Head of Posturology Department, Hearing and \\ Balance Rehabilitation, Institute of Physiotherapy, Faculty of Medicine and Health Sciences, Jan Kochanowski \\ University, Kielce, Al. IX Wieków Kielc 19, 25-317 Kielce, Poland. Tel: 48-603-703-926. E-mail: \\ jwilczyński@onet.pl
}

Received: July 8, 2018

doi:10.5539/mas.v12n9p19
Accepted: July 27, 2018

Online Published: August 8, 2018

\begin{abstract}
The objective of the study was evaluation of the relationships between location of scoliosis and postural reactions in girls aged 7-18. The study included 28 girls aged 7-18 with lateral curvature of the spine and scoliotic posture. Selection of the examined girls was targeted. The children were treated in the Inter-School Centre for Corrective and Compensatory Gymnastics in Starachowice. The study was conducted in June 2011. Digital Exhibeon radiograms were applied to determine the location of the curvature. Postural reactions were evaluated using the static-dynamic platform Tecnobody ST 310 Plus Stability System. The variables were verified for normality of the distribution by means of Shapiro-Wilk test. The variability of the quantitative characteristics with respect to categorial characteristics was verified by using one-way and two-way repeated measures ANOVA. In the case of significant main results or interactions, the Bonferroni test and Tukey test were applied as a post hoc analysis. The $\mathrm{p}$ values $\mathrm{p}<0.05$ were considered statistically significant. Analysis of variance showed significant relationships between Average Forward-Backward Speed, Perimeter, Ellipse Area in open eyes test (OE), and location of the curvature. The highest amplitudes of the reactions Average Forward-Backward Speer, Perimeter, Ellipse Area in open eyes test (OE) were observed in lumbar curvatures. In examination with eyes closed (CE), a correlation was found between the location of the curvature and Forward-Backward Standard Deviation, Average Forward-Backward Speer, and Perimeter. The highest amplitudes of reactions Average Forward-Backward Speer, Perimeter, Ellipse Area in eyes closed test (CE) were noted also in lumbar curvatures. The comparative analysis of variance of postural reactions with respect to the location of the secondary curvature showed significant results only for Average Forward-Backward Speed (OE). Average Forward-Backward Speed (OE) was the highest in curvatures with thoracic location.
\end{abstract}

Keywords: lateral curvature of the spine, moire method, postural reactions, centre of pressure (COP)

\section{Introduction}

In scoliosis, increasingly more often attention is paid to discrete neurological changes. This unaesthetic, and sometimes simply catastrophic illness which limits fitness, and efficiency of the body is a mechanically and biologically justified reaction to minimal disorders in the CNS. These changes will probably not be determined by the orthopaedists alone, and wide cooperation will be needed with neuropathologists (Głowacki, Kotwicki $\&$ Pucher, 2008). In scoliosis, changes in the bone and muscle tissue are of a secondary character, resulting from the uneven axial loading of the spine. According to the location, five basic types of spinal curvatures are distinguished: cervical-thoracic, thoracic (most often right-sided), thoracic-lumbar, lumbar (most often left-sided), double thoracic and lumbar (most frequently thoracic right-sided, and lumbar left-sided). Primary cervical-thoracic curvatures are the most rarely occurring type of idiopathic scoliosis (approximately 1.5\%); however, they lead to severe deformations (Hosseinpour-Feizi et al. 2011; Burwell et al. 2012). The peak of curvature is most often placed on the level of $\mathrm{Th}_{3}$ vertebra. Primary thoracic curvatures are most frequent $(44 \%)$, and are most often directed to the right side $(90 \%)$. The peak of this curvature is generally placed in the segment 
$\mathrm{Th}_{7}$ - $\mathrm{Th}_{9}$. Primary thoracic-lumbar curvatures are substantially similar to thoracic curvatures; however, their peak is located lower, on the levels $\mathrm{Th}_{11}-\mathrm{L}_{1}$. These curvatures cause substantial changes of posture, due to the difficulty in linear compensation and a considerable lateral transposition of the trunk. Primary lumbar curvatures occur in the period of adolescence (Chen \& Lerman, 2012; De Sèze \& Cugy, 2012). The peak of this curvature is placed in the segment $\mathrm{L}_{2}-\mathrm{L}_{3}$. The curvature has great possibilities for linear remediation. These curvatures, after the completion of growth, may be the cause of considerable pain complaints. Double thoracic and lumbar curvatures in the thoracic segment are most often directed to the right side. The angle of both curvatures is approximately equal. These curvatures occur in various periods of growth, and the development of the curvature during adolescence substantially improves the prognosis. Double curvatures are generally linearly remedied, which does not result in greater postural disorders. The radiological image is always worse than the clinical changes of the posture (Joo, Rogers \& Donohoe, 2012; Michiel et al. 2012; Weiss, 2012).

Postural reactions are the element of body balance. Balance is a specified state of the postural system which is characterized by an upright orientation of the body, obtained due the compensation of forces exerting an effect on the body and their moments of force. Balance is provided by the nervous system by reflexive flexion of the proper groups of muscles, called postural or antigravity muscles. Analysis of individual postural reactions provides additional information concerning body balance. These are sways of the body in the saggital and frontal planes, i.e. dislocations of centre of feet pressure (COP). Computed posturography creates the possibility of an indirect assessment of the function of the nervous system by the measurement of the centre of pressure (COP) which characterizes the maintenance of balance in an upright position. The dislocations of individual segments of the body observed in scoliosis should, theoretically, affect the character of postural reactions (COP), and vice versa, the disorders of postural reactions may exert an effect on the pathoetiology of scoliosis. In our opinion, the disorders of postural reactions are primary and precede scoliotic changes. The objective of the study was evaluation of the relationships between location of scoliosis and postural reactions in girls aged 7-18.

\section{Methods}

\subsection{Participant (Subject) Characteristics}

The study covered 28 girls aged 7-18 with lateral curvature of the spine and scoliotic posture. Selection of the girls was targeted. The children attended the Inter-School Centre for Corrective and Compensatory Gymnastics in Starachowice. The study was carried out in June 2011. The examined girls were divided into 3 age groups: $7-11,12-14$, and $15-18$. In the group aged $7-11$ there were $8(28.57 \%)$ girls, in the group aged 12-14 - 13 (46.43\%), and in the group aged 15-18 - 7 (25.00\%). Anthropometric parameters were determined (Tab. 1).

Table 1. Antropometric parameters of the tested (Note 1)

\begin{tabular}{llllllllll}
\hline $\begin{array}{l}\text { Features } \\
\text { of the tested }\end{array}$ & $\mathbf{n}$ & $\mathbf{x}$ & $\mathbf{m e d}$ & $\mathbf{m i n}$ & $\mathbf{m a x}$ & $\mathbf{r}$ & $\mathbf{s}$ & slant & $\mathbf{k}$ \\
\hline Age & 28 & 153,39 & 154 & 120 & 174 & 54 & 13,04 & $-0,594$ & 0,121 \\
Body height & 28 & 153,39 & 154 & 120 & 174 & 54 & 13,04 & $-0,594$ & 0,121 \\
Body mass & 28 & 43,14 & 45,5 & 19 & 60 & 41 & 9,76 & $-0,630$ & $-0,085$ \\
BMI & 28 & 18,05 & 18,35 & 13,19 & 22,21 & 9,01 & 2,04 & $-0,264$ & $-0,159$ \\
\hline
\end{tabular}

The location of the curvature was determined using the Exhibeon digital radiograms.

\subsection{Research Design}

The radiograms were performed in a free-standing position, in anterior-posterior and lateral projection. X-ray covered lumbar, thoracic and cervical spine, as well as the pelvis with the hip joints. On the X-ray of the spine displayed on the computer screen, the Cobb angle was plotted and location of the curvature. Scoliotic posture 1-9 ${ }^{\circ}$ was distinguished, as well as lateral curvature of the spine $\geq 10^{\circ}$, thoracic, lumbar, and thoracic and lumbar curvatures. Postural reactions were evaluated using the static-dynamic platform Tecnobody ST 310 Plus Stability System. The selected parameters were statistically analyzed, which registered the sways of the centre of pressure (COP): the perimeter; this is the total path length of the displacement of the COP in both planes during oscillation (mm); Ellipse Area - the total surface covered by the COP displacements in both planes during oscillation $\left(\mathrm{mm}^{2}\right)$; standard deviation Y (Forward-Backward Standard Deviation) - the mean oscillation along the axis $\mathrm{Y}(\mathrm{mm})$, mean anterior-posterior sway $(\mathrm{mm})$ - mean distance between the extreme sways of the centre of pressure in the saggital plane; standard deviation X (Medium-Lateral Standard Deviation) - the mean oscillation along the axis $X(\mathrm{~mm})$, and mean lateral sway $(\mathrm{mm})$, i.e. the mean distance between the extreme 
sways of the centre of pressure in the lateral plane; the mean loading point $\mathrm{X}$ (Average COPX) with reference to the platform axis; gives lateral coordinates $\mathrm{X}(\mathrm{mm})$; the mean loading point $\mathrm{Y}$ (Average COPY) with reference to the platform axis; gives anterior-posterior coordinates $\mathrm{Y}(\mathrm{mm})$; anterior-posterior velocity (Average Forward-Backward Speed), i.e. the mean speed of oscillation along axis $\mathrm{Y}(\mathrm{mm} / \mathrm{s})$ - a quotient of the length of sways of the centre of pressure during the test, which indirectly provides information concerning the dynamics of the regulation of the process of postural stability in an upright position; lateral velocity (Average Medium-Lateral Speed $)$, i.e. the mean speed of oscillation along the axis X $(\mathrm{mm} / \mathrm{s})$ - a quotient of the length of sways of the centre of pressure during the test which indirectly provides information concerning the dynamics of the process of regulation of postural stability in an upright position; ratio of perimeters (Perimeter Ratio) - the ratio between perimeter with eyes closed (CE), and the perimeter with eyes open (OE) in the Romberg test; Area Ratio - the ratio between the Ellipse Area with eyes closed (CE) and the area with open eyes (OE) in the Romberg test.

\subsection{Measures and Covariates}

Persons with postural disorders, as well as those in whom free-standing was disturbed, showed generally higher values of all the above-mentioned parameters. Similarly, higher sways were observed in children. According to the conformity of variables distribution with normal distribution, the values of skewness and curtosis, parametric and non-parametric tests were applied. The variables were verified for the normality of distribution using the Shapiro-Wilk test. For qualitative and discrete variables numerical and percentage distributions were calculated. Variability of quantitative characteristics according to categorical characteristics (age group, study options) were verified by means of one-way or two-way repeated measures ANOVA. In the case of significant main effects or interactions, the Bonferroni test and Tukey test were applied as a post hoc analysis. The $\mathrm{p}$ values $\mathrm{p}<0.05$ were considered statistically significant.

\section{Results and Discussion}

Primary curvatures included: 10 (36\%) thoracic (thoracalis), 6 (21\%) lumbar (lumbalis), and 12 (43\%). thoracic and lumbar (thoracalis-lumbalis). The location of primary curvature was not related with respondents' age $\left(\chi^{2}=\right.$ 7.94; $\mathrm{p}=0.94$ (Tab. 2). In 17 (60.71\%) respondents, secondary curvature did not occur. There were 2 (7.14\%) secondary thoracic curvatures (thoracalis), 9 (32.14\%), lumbar curvatures (lumbalis), whereas no thoracic and lumbar curvatures (thoracali-lumbalis) were found. The location of secondary curvature was also not related with the respondents' age $\left(\chi^{2}=7.258875 ; p=0.12283\right)$ (Tab. 2). Comparative analysis of postural reactions was performed (dependent variables) with respect to the location of primary curvature (independent variable). Postural reactions with eyes open (OE) and with closed eyes (CE) were separately analyzed. The comparative analysis of variance of postural reactions with respect to primary curvature showed significant results for: Average Forward-Backward Speed $(\mathrm{OE})(\mathrm{p}=0.0037)$, Perimeter $(\mathrm{OE})(\mathrm{p}=0.0058)$, Ellipse Area $(\mathrm{OE})(\mathrm{p}=0.0356)$, Forward-Backward Standard Deviation (CE), $(\mathrm{p}=0.0054)$, Average Forward-Backward Speed (CE) $(\mathrm{p}=0.0225)$, Perimeter (CE) $(\mathrm{p}=0.0326)$ (Tab. 2).

Table 2. Location of scoliosis and postural reactions

\begin{tabular}{|c|c|c|c|c|c|c|c|}
\hline \multicolumn{8}{|c|}{$\begin{array}{l}\text { Curvature of the spine primary } \\
\text { Average Forward-Backward Speed (OE) }\end{array}$} \\
\hline Age groups & $\mathrm{n}$ & $x$ & $\mathrm{~S}$ & $\min$ & $\max$ & $-95,00 \%$ & $95,00 \%$ \\
\hline Thoracic & 10 & 8,900 & 2,558 & 7 & 11 & 7,070 & 10,730 \\
\hline Lumbar & 6 & 17,833 & 7,885 & 12 & 14 & 9,559 & 26,108 \\
\hline Thoraco-lumbar & 12 & 11,583 & 3,872 & 15 & 18 & 9,123 & 14,043 \\
\hline Total & 28 & 11,964 & 5,568 & 7 & 18 & 9,805 & 14,123 \\
\hline \multicolumn{8}{|l|}{ Perimeter (OE) } \\
\hline Age groups & $\mathrm{n}$ & $\mathrm{x}$ & $\mathrm{s}$ & $\min$ & $\max$ & $-95,00 \%$ & $95,00 \%$ \\
\hline Thoracic & 10 & 440,000 & 130,713 & 248 & 701 & 346,493 & 533,507 \\
\hline Lumbar & 6 & 742,000 & 264,669 & 487 & 1079 & 464,247 & 1019,753 \\
\hline Thoraco-lumbar & 12 & 521,083 & 128,615 & 343 & 760 & 439,366 & 602,801 \\
\hline Total & 28 & 539,464 & 195,798 & 248 & 1079 & 463,542 & 615,387 \\
\hline \multicolumn{8}{|c|}{ Ellipse Area (OE) } \\
\hline Age groups & $\mathrm{n}$ & $\mathrm{x}$ & $\mathrm{s}$ & $\min$ & $\max$ & $-95,00 \%$ & $95,00 \%$ \\
\hline Thoracic & 10 & 303,700 & 181,187 & 115 & 597 & 174,087 & 433,313 \\
\hline Lumbar & 6 & 711,000 & 478,062 & 359 & 1660 & 209,305 & 1212,695 \\
\hline Thoraco-lumbar & 12 & 435,500 & 234,552 & 102 & 993 & 286,473 & 584,527 \\
\hline
\end{tabular}




\begin{tabular}{|c|c|c|c|c|c|c|c|}
\hline Total & 28 & 447,464 & 314,374 & 102 & 1660 & 325,563 & 569,366 \\
\hline \multicolumn{8}{|c|}{ Forward-Backward Standard Deviation (CE) } \\
\hline Age groups & $\mathrm{n}$ & $\mathrm{x}$ & $\mathrm{s}$ & $\min$ & $\max$ & $-95,00 \%$ & $95,00 \%$ \\
\hline Thoracic & 10 & 5,100 & 0,994 & 3 & 6 & 4,389 & 5,811 \\
\hline Lumbar & 6 & 10,667 & 4,274 & 7 & 16 & 6,181 & 15,152 \\
\hline Thoraco-lumbar & 12 & 7,500 & 3,371 & 3 & 14 & 5,358 & 9,642 \\
\hline Total & 28 & 7,321 & 3,560 & 3 & 16 & 5,941 & 8,702 \\
\hline \multicolumn{8}{|c|}{ Average Forward-Backward Speed (CE) } \\
\hline Age groups & $\mathrm{n}$ & $\mathrm{x}$ & $\mathrm{s}$ & $\min$ & $\max$ & $-95,00 \%$ & $95,00 \%$ \\
\hline Thoracic & 10 & 13,200 & 3,225 & 9 & 18 & 10,893 & 15,507 \\
\hline Lumbar & 6 & 22,333 & 5,317 & 18 & 32 & 16,754 & 27,913 \\
\hline Thoraco-lumbar & 12 & 18,167 & 7,941 & 8 & 36 & 13,121 & 23,212 \\
\hline Total & 28 & 17,286 & 6,825 & 8 & 36 & 14,639 & 19,932 \\
\hline \multicolumn{8}{|l|}{ Perimeter (CE) } \\
\hline Age groups & $\mathrm{n}$ & $\mathrm{x}$ & $\mathrm{s}$ & $\min$ & $\max$ & $-95,00 \%$ & $95,00 \%$ \\
\hline Thoracic & 10 & 619,200 & 146,277 & 449 & 896 & 514,560 & 723,841 \\
\hline Lumbar & 6 & 907,833 & 189,612 & 730 & 1199 & 708,848 & 1106,819 \\
\hline Thoraco-lumbar & 12 & 801,167 & 258,921 & 499 & 1330 & 636,656 & 965,677 \\
\hline Total & 28 & 759,036 & 232,496 & 449 & 1330 & 668,883 & 849,188 \\
\hline \multicolumn{8}{|c|}{$\begin{array}{l}\text { Secondary curvature of the spine } \\
\text { Average Forward-Backward Speed (OE) }\end{array}$} \\
\hline Age groups & $\mathrm{n}$ & $\mathrm{x}$ & $\mathrm{s}$ & $\min$ & $\max$ & $-95,00 \%$ & $95,00 \%$ \\
\hline Brak skrzywienia & 17 & 12,588 & 4,459 & 7 & 21 & 10,296 & 14,881 \\
\hline Thoracic & 2 & 21,000 & 14,142 & 11 & 31 & $-106,062$ & 148,062 \\
\hline Lumbar & 9 & 8,778 & 2,682 & 5 & 14 & 6,716 & 10,840 \\
\hline Total & 28 & 11,964 & 5,568 & 5 & 31 & 9,805 & 14,123 \\
\hline
\end{tabular}

The mean Average Forward-Backward Speed (OE) was $(11.964 \mathrm{~mm} / \mathrm{s})$. Average Forward-Backward Speed (OE) was the highest in curvatures with lumbar location $(\mathrm{L})(17.83 \mathrm{~mm} / \mathrm{s})$, in thoracic and lumbar curvatures (Th-L) $11.583 \mathrm{~mm} / \mathrm{s}$, while its lowest value was observed in thoracic curvatures (Th) $-8.900 \mathrm{~mm} / \mathrm{s}$ (Tab. 3). The mean Perimeter (OE) was $539.464 \mathrm{~mm}^{2}$. Ellipse Reaction Perimeter (OE) was the highest in curvatures with lumbar location (L) - $742 \mathrm{~mm}$, in thoracic and lumbar locations (Th-L) $-521 \mathrm{~mm}$, while it was the lowest in curvatures with thoracic location (Th) - $440 \mathrm{~mm}$ (Tab. 3). The mean Ellipse Area (OE) was $447.464 \mathrm{~mm}^{2}$. Ellipse Area (OE) was the highest in curvatures with lumbar location (L) $-711.000 \mathrm{~mm}^{2}$, whereas in thoracic and lumbar curvatures (Th-L) - $303.700 \mathrm{~mm}^{2}$, and it was the lowest in thoracic curvatures (Th) $-435.500 \mathrm{~mm}^{2}$ (Tab. 3). Mean Forward-Backward Standard Deviation (CE) - $7.321 \mathrm{~mm}$. Forward-Backward Standard Deviation (CE), the highest in curvatures with lumbar location (L) - $10.667 \mathrm{~mm}$, in thoracic and lumbar curvatures (Th-L) $7.500 \mathrm{~mm}$, and was the lowest in thoracic curvatures (Th) - $5.100 \mathrm{~mm}$ (Tab. 3). Mean Average Forward-Backward Speed (CE) - 13.200mm/s. Mean Average Forward-Backward Speed (CE) was the highest in curvatures with a lumbar location (L) $-22.333 \mathrm{~mm} / \mathrm{s}$; in thoracic and lumbar curvatures (Th-L) $-18.167 \mathrm{~mm} / \mathrm{s}$, while it was the lowest in thoracic curvatures (Th) $-13.200 \mathrm{~mm} / \mathrm{s}$ (Tab. 3). Mean Perimeter (CE) $-759.036 \mathrm{~mm}^{2}$. Perimeter (CE) was the highest in curvatures with lumbar location (L) $-907.833 \mathrm{~mm}^{2}$ ), and thoracic and lumbar curvatures (Th-L) - $801.167 \mathrm{~mm}^{2}$, and was the lowest in thoracic curvatures (Th) $-619.200 \mathrm{~mm}^{2}$ (Tab. 3). Comparative analysis of postural reactions was performed (dependent variables) also with respect to the location of the secondary curvature (independent variable). Postural reactions with open eyes (OE) and with closed eyes (CE) were analyzed separately. Comparative analysis of variance of postural reactions with respect to the location of secondary curvature showed significant results only for Average Forward-Backward Speed (OE) $(\mathrm{p}=0.0282)($ Tab. 3). Here, the mean Average Forward-Backward Speed (OE) was $11.964 \mathrm{~mm} / \mathrm{s}$. Average Forward-Backward Speed (OE) was the highest in curvatures with thoracic location (Th) $-21.000 \mathrm{~mm} / \mathrm{s}$, in lumbar curvatures (L) $-8.778 \mathrm{~mm} / \mathrm{s}$. Average Forward-Backward Speer (OE) in 17 respondents in whom secondary curvature had not developed was $12.588 \mathrm{~mm} / \mathrm{s}$ (Tab. 3). 
Table 3. Analysis of variance of location scoliosis and postural reactions (Note 2)

\begin{tabular}{|c|c|c|c|c|c|c|c|c|}
\hline \multicolumn{9}{|c|}{ Curvature of the spine primary } \\
\hline Dependent variables (OE) & $\begin{array}{l}\text { SS } \\
\text { Effect }\end{array}$ & $\begin{array}{l}\text { DF } \\
\text { Effect }\end{array}$ & $\begin{array}{l}\text { MS } \\
\text { Effect }\end{array}$ & $\begin{array}{l}\text { SS } \\
\text { Error }\end{array}$ & $\begin{array}{l}\text { DF } \\
\text { Error }\end{array}$ & $\begin{array}{l}\text { MS } \\
\text { Error }\end{array}$ & $\mathbf{F}$ & $\mathbf{p}$ \\
\hline $\mathrm{AX}(\mathrm{OE})$ & 1 & 2 & 0 & 21 & 25 & 0,8 & 0,461 & 0,6360 \\
\hline $\mathrm{AY}(\mathrm{OE})$ & 41 & 2 & 20 & 1065 & 25 & 42,6 & 0,478 & 0,6253 \\
\hline FBSD (OE) & 27 & 2 & 13 & 148 & 25 & 5,9 & 2,262 & 0,1251 \\
\hline $\operatorname{MLSD}(\mathrm{OE})$ & 13 & 2 & 7 & 81 & 25 & 3,2 & 2,078 & 0,1463 \\
\hline AFBS (OE) & 302 & 2 & 151 & 535 & 25 & 21,4 & 7,068 & $\mathbf{0 , 0 0 3 7}$ \\
\hline AMLS (OE) & 52 & 2 & 26 & 359 & 25 & 14,4 & 1,797 & 0,1866 \\
\hline Perimeter (OE) & 349110 & 2 & 174555 & 685981 & 25 & 27439,2 & 6,362 & 0,0058 \\
\hline Ellipse Area $(\mathrm{OE})$ & 625106 & 2 & 312553 & 2043335 & 25 & 81733,4 & 3,824 & 0,0356 \\
\hline Dependent variables (CE) & $\begin{array}{l}\text { SS } \\
\text { Effect }\end{array}$ & $\begin{array}{l}\text { DF } \\
\text { Effect }\end{array}$ & $\begin{array}{l}\text { MS } \\
\text { Effect }\end{array}$ & $\begin{array}{l}\text { SS } \\
\text { Error }\end{array}$ & $\begin{array}{l}\text { DF } \\
\text { Error }\end{array}$ & $\begin{array}{l}\text { MS } \\
\text { Error }\end{array}$ & $\mathrm{F}$ & $\mathrm{p}$ \\
\hline $\mathrm{AX}(\mathrm{CE})$ & 17 & 2 & 9 & 445 & 25 & 17,8 & 0,483 & 0,6223 \\
\hline $\mathrm{AY}(\mathrm{CE})$ & 133 & 2 & 66 & 994 & 25 & 39,8 & 1,671 & 0,2085 \\
\hline FBSD (CE) & 117 & 2 & 58 & 225 & 25 & 9 & 6,486 & 0,0054 \\
\hline MLSD (CE) & 13 & 2 & 7 & 172 & 25 & 6,9 & 0,954 & 0,3988 \\
\hline AFBS (CE) & 329 & 2 & 165 & 929 & 25 & 37,1 & 4,430 & 0,0225 \\
\hline AMLS (CE) & 45 & 2 & 22 & 412 & 25 & 16,5 & 1,352 & 0,2769 \\
\hline Perimeter (CE) & 349685 & 2 & 174842 & 1109778 & 25 & 44391,1 & 3,939 & 0,0326 \\
\hline Ellipse Area (CE) & 2689006 & 2 & 1344503 & 13787414 & 25 & 551496,6 & 2,438 & 0,1078 \\
\hline Perimeter Ratio & 1787 & 2 & 894 & 34081 & 25 & 1363,2 & 0,656 & 0,5279 \\
\hline Area Ratio & 9361 & 2 & 4680 & 590344 & 25 & 23613,8 & 0,198 & 0,8215 \\
\hline \multicolumn{9}{|c|}{ Secondary curvature of the spine } \\
\hline Dependent variables $(\mathrm{OE})$ & $\begin{array}{l}\text { SS } \\
\text { Effect }\end{array}$ & $\begin{array}{l}\text { DF } \\
\text { Effect }\end{array}$ & $\begin{array}{l}\text { MS } \\
\text { Effect } \\
\end{array}$ & $\begin{array}{l}\text { SS } \\
\text { Error } \\
\end{array}$ & $\begin{array}{l}\text { DF } \\
\text { Error } \\
\end{array}$ & $\begin{array}{l}\text { MS } \\
\text { Error } \\
\end{array}$ & $\mathbf{F}$ & $\mathbf{p}$ \\
\hline $\mathrm{AX}(\mathrm{OE})$ & 1 & 1 & 1 & 20 & 24 & 0,8 & 0,626 & 0,4367 \\
\hline $\mathrm{AY}(\mathrm{OE})$ & 58 & 1 & 58 & 848 & 24 & 35,3 & 1,639 & 0,2127 \\
\hline FBSD (OE) & 13 & 1 & 13 & 141 & 24 & 5,9 & 2,241 & 0,1474 \\
\hline MLSD (OE) & 6 & 1 & 6 & 89 & 24 & 3,7 & 1,636 & 0,2131 \\
\hline AFBS (OE) & 85 & 1 & 85 & 376 & 24 & 15,7 & 5,459 & 0,0282 \\
\hline AMLS (OE) & 14 & 1 & 14 & 396 & 24 & 16,5 & 0,834 & 0,3703 \\
\hline Perimeter (OE) & 90453 & 1 & 90453 & 641662 & 24 & 26735,9 & 3,383 & 0,0783 \\
\hline Ellipse Area (OE) & 229757 & 1 & 229757 & 2368102 & 24 & 98670,9 & 2,329 & 0,1401 \\
\hline Dependent variables (CE) & $\begin{array}{l}\text { SS } \\
\text { Effect }\end{array}$ & $\begin{array}{l}\text { DF } \\
\text { Effect }\end{array}$ & $\begin{array}{l}\text { MS } \\
\text { Effect }\end{array}$ & $\begin{array}{l}\text { SS } \\
\text { Error }\end{array}$ & $\begin{array}{l}\text { DF } \\
\text { Error }\end{array}$ & $\begin{array}{l}\text { MS } \\
\text { Error }\end{array}$ & $\mathrm{F}$ & $\mathrm{p}$ \\
\hline $\mathrm{AX}(\mathrm{CE})$ & 26 & 1 & 26 & 422 & 24 & 17,6 & 1,502 & 0,2323 \\
\hline AY (CE) & 7 & 1 & 7 & 1058 & 24 & 44,1 & 0,169 & 0,6849 \\
\hline FBSD (CE) & 38 & 1 & 38 & 226 & 24 & 9,4 & 4,065 & 0,0551 \\
\hline MLSD (CE) & 2 & 1 & 2 & 178 & 24 & 7,4 & 0,332 & 0,5696 \\
\hline AFBS (CE) & 129 & 1 & 129 & 893 & 24 & 37,2 & 3,462 & 0,0751 \\
\hline AMLS (CE) & 30 & 1 & 30 & 414 & 24 & 17,2 & 1,746 & 0,1989 \\
\hline Perimeter (CE) & 158121 & 1 & 158121 & 1100042 & 24 & 45835,1 & 3,450 & 0,0756 \\
\hline Ellipse Area (CE) & 1180583 & 1 & 1180583 & 13678478 & 24 & 569936,6 & 2,071 & 0,1630 \\
\hline Perimeter Ratio & 301 & 1 & 301 & 34162 & 24 & 1423,4 & 0,212 & 0,6495 \\
\hline Area Ratio & 407 & 1 & 407 & 590711 & 24 & 24613 & 0,017 & 0,8987 \\
\hline
\end{tabular}

Post hoc analysis - detailed comparisons showed a significant difference in Average Forward-Backward Speed $(\mathrm{OE})$ between thoracic location $(\mathrm{Th})$ and lumbar location $(\mathrm{L})(\mathrm{p}=0.0072)$, and thoracic location $(\mathrm{Th})$ and thoracic and lumbar ( $\mathrm{p}=0.0072)$ (Tab. 4). Post hoc analysis showed a significant difference in Perimeter (OE) between thoracic location (Th) and lumbar (L) $(\mathrm{p}=0.0046)$, and between thoracic location $(\mathrm{Th})$ and thoracic and lumbar location (Th-L) ( $\mathrm{p}=0.0342)$ (Tab. 4). Post hoc analysis did not show any differences between Ellipse Area (OE) and location of the curvature of the spine (Tab. 4). Post hoc analysis also indicated a significant difference in 
Forward-Backward Standard Deviation (CE) between thoracic and lumbar location (Th-L) (p=0.0098) (Tab. 4). Post hoc analysis further showed a significant difference in Average Forward-Backward Speed (OE) between thoracic location (Th) and lumbar location (L) $(\mathrm{p}=0.0400)$ (Tab. 4). Post hoc analysis, however, did not show any significant differences between Perimeter (CE) and location of the curvature of the spine (Tab. 4).

Table 4. Post hoc analysis of postural reactions in relation to the location of primary curvature

\begin{tabular}{|c|c|c|c|}
\hline \multicolumn{4}{|c|}{ Average Forward-Backward Speed (OE) } \\
\hline \multirow{2}{*}{ Independent variables } & (1) & (2) & (3) \\
\hline & $\mathrm{M}=8,90$ & $\mathrm{M}=17,83$ & $\mathrm{M}=11,58$ \\
\hline \multirow{3}{*}{$\begin{array}{l}\text { Thoracic (Th) (1) } \\
\text { Lumbar (L) (2) } \\
\text { Thoraco-lumbar (Th-L) (3) }\end{array}$} & & $\mathbf{0 , 0 0 7 2}$ & 0,40 \\
\hline & $\mathbf{0 , 0 0 7 2}$ & & 0,06 \\
\hline & 0,4098 & 0,06 & \\
\hline \multirow[b]{2}{*}{ Independent variables } & $(1)$ & (2) & (3) \\
\hline & $M=440,00$ & $\mathrm{M}=742,00$ & $\mathrm{M}=521,08$ \\
\hline \multicolumn{4}{|l|}{ Perimeter (OE) } \\
\hline \multirow[t]{2}{*}{ Independent variables } & (1) & (2) & (3) \\
\hline & $\mathrm{M}=440,000$ & $\mathrm{M}=742,00$ & $\mathrm{M}=521,08$ \\
\hline \multirow{4}{*}{$\begin{array}{l}\text { Thoracic (Th) (1) } \\
\text { Lumbar (L) (2) } \\
\text { Thoraco-lumbar (Th-L) (3) } \\
\text { Ellipse Area (OE) }\end{array}$} & & 0,0046 & 0,4973 \\
\hline & 0,0046 & & 0,0342 \\
\hline & 0,4973 & 0,0342 & \\
\hline & & & \\
\hline \multirow{2}{*}{ Independent variables } & (1) & (2) & (3) \\
\hline & $\mathrm{M}=303,700$ & $\mathrm{M}=711,00$ & $M=435,05$ \\
\hline \multirow{4}{*}{$\begin{array}{l}\text { Thoracic (Th) (1) } \\
\text { Lumbar (L) (2) } \\
\text { Thoraco-lumbar (Th-L) (3) }\end{array}$} & & 0,0526 & 0,5649 \\
\hline & 0,0526 & & 0,2368 \\
\hline & 0,5649 & 0,2368 & \\
\hline & ard Deviati & $n(C E)$ & \\
\hline \multirow{2}{*}{ Independent variables } & (1) & (2) & (3) \\
\hline & $\mathrm{M}=5,1$ & $M=10,66$ & $M=7,5$ \\
\hline \multirow{4}{*}{$\begin{array}{l}\text { Thoracic (Th) (1) } \\
\text { Lumbar (L) (2) } \\
\text { Thoraco-lumbar (Th-L) (3) } \\
\text { Average Forward-Backwa }\end{array}$} & & 0,0098 & 0,1942 \\
\hline & 0,0098 & & 0,1815 \\
\hline & 0,1942 & 0,1815 & \\
\hline & rd Speed (C) & & \\
\hline \multirow{2}{*}{ Independent variables } & (1) & (2) & (3) \\
\hline & $M=13,200$ & $M=22,333$ & $M=18,167$ \\
\hline \multirow{4}{*}{$\begin{array}{l}\text { Thoracic (Th) (1) } \\
\text { Lumbar (L) (2) } \\
\text { Thoraco-lumbar (Th-L) (3) } \\
\text { Perimeter (CE) }\end{array}$} & & 0,0400 & 0,1831 \\
\hline & 0,0400 & & 0,4734 \\
\hline & 0,1831 & 0,4734 & \\
\hline & & & \\
\hline \multirow{2}{*}{ Independent variables } & (1) & (2) & (3) \\
\hline & $M=619,20$ & $M=907,83$ & $\mathrm{M}=801,17$ \\
\hline \multirow{3}{*}{$\begin{array}{l}\text { Thoracic (Th) (1) } \\
\text { Lumbar (L) (2) } \\
\text { Thoraco-lumbar (Th-L) (3) }\end{array}$} & & 0,0641 & 0,1510 \\
\hline & 0,0641 & & 0,6596 \\
\hline & 0,1510 & 0,6596 & \\
\hline
\end{tabular}

In recent years, posturographic studies in lateral curvatures of the spine were conducted by, among others, Allard et al. (2004), Bennett et al. (2004), Bruyneel et al. (2010), Eshraghi et al. (2009), Lee et al. (2012), Shi et al. (2011), Tao et al. (2012), Abreu et al. (2012). In these studies, the researchers confirmed the effect of these disorders on the course of scoliosis. In Poland, this problem was undertaken by, among others, Ostrowska, Rożek-Piechura, and Skolimowski (2006). The goal of their study was an attempt to use the model of mathematical modelling for the assessment of motor characteristics of children with idiopathic scoliosis while maintaining balance in an upright position in the presence of external interferences. The study was conducted in a group of 42 children aged 13-18 with idiopathic scoliosis, and in a control group of 40 healthy children. Body balance was assessed by the stabilographic method using the force platform recording the COP signal. The 
examined persons who stood on the stabilograph were unexpectedly lightly pushed. The result was the mean value from 10 measurements. Motor parameters of the examined persons were determined based on the values of equations coefficients calculated from the model of the balance system applied. Analysis of results showed significant differences in the way of reacting to balance disturbance. Persons with scoliosis were characterized by greater body sways, compared to the healthy individuals. The speed of losing balance after its disturbance in these persons was slower, and depended on the dimension of curvature. The larger the curvature, the lower the process of balance loss, with lower speed and acceleration, and the longer the time needed for stabilization of posture. Upright position in children with idiopathic scoliosis was more susceptible to balance disturbances and characterized by worse stability. The reaction on the part of the nervous system to balance disorder in scoliosis was clearly delayed and characterized by lower impulsiveness. According to Chamela-Bilińska et al. (2005), any changes in the region of the trunk which impair the functioning of the control or executing systems, are also reflected by postural stability. In her studies, Chamera-Bilińska confirmed that any lateral curvature of the spine creates risk for the stability of the body. For the child's stability, it does not matter at which segment of the spine the curvature is located, nor the side of the curvature of the arch. Children with idiopathic scoliosis are characterized by worse control of body stability, compared to healthy children.

In own studies of 2005, significant differences between girls and boys were observed with respect to the path length, mean loading point $\mathrm{Y}$, lateral speed, anteroposterior speed, and mean sway X. Only the mean loading point $Y$ was significantly higher in girls in both tests $(\mathrm{OE}, \mathrm{CE})$. Girls obtained lower amplitudes of the examined parameters in both tests $(\mathrm{OE}, \mathrm{CE})$. A significant effect of age was observed for the mean loading point $\mathrm{Y}$ and anteroposterior speed. In girls, in open eyes test (OE), the mean loading point $Y$ increased with age, while in the closed eyes test (CE) this parameter was the lowest in 12-year-olds, followed by those aged 13, 15 and 14. In boys, in open eyes test (OE), the mean loading point $\mathrm{Y}$ was the lowest in those aged 13, followed by 12, 14, 15 -year-olds; in closed eyes test (CE) this paramater increased with age. Significant differences in the test with open eyes (OE) and closed eyes (CE) (Romberg test) were confirmed for the path length, mean loading point X, lateral speed, and the mean sway $\mathrm{Y}$. Only the mean loading point $\mathrm{X}$ in closed eyes test (CE) increased. Significant relationships were also found between posture defects in the saggital plane and lateral curvatures of the spine, and anteroposterior speed, the mean loading point $\mathrm{Y}$, the mean sway $\mathrm{X}$ and the mean sway $\mathrm{Y}$. lateral curvatures of the spine and defects in the saggital plane are accompanied by a significant increase in the anteroposterior speed (Wilczyński et al. 2018).

Significant relationships found between the localization of the curvature of the spine and postural reactions confirm that these curvatures exert a substantial effect on the biochemical and functional balance of the spine and body posture. While selecting methods of treatment of scoliosis the localization of curvatures should be considered, and each case should be individually approached.

\section{Conclusions}

Analysis of variance showed significant relationships between Average Forward-Backward Speed, Perimeter, Ellipse Area in open eyes test (OE, and the localization of the curvature. The highest amplitudes of the reactions Average Forward-Backward Speer, Perimeter, Ellipse Area in open eyes test (OE) were observed in lumbar curvatures. In the test with closed eyes (CE) with the localization of the curvature, the reactions Forward-Backward Standard Deviation, Average Forward-Backward Speer, Perimeter were significantly related. The highest amplitudes of reactions Average Forward-Backward Speer, Perimeter, Ellipse Area in closed eyes test (CE) were also observed in lumbar curvatures. Comparative analysis of variance of postural reactions with respect to the localization of the secondary curvature showed significant results only for Average Forward-Backward Speed (OE). Average Forward-Backward Speed (OE) was the highest in curvatures with thoracic localization.

\section{Acknowledgments}

This research did not receive any specific grant from funding agencies in the public, commercial, or not-for-profit sectors.

\section{References}

Abreu, D. C., Gome, M. M., \& Santiago, H. A., et al. (2012). What is the influence of surgical treatment of adolescent idiopathic scoliosis on postural control? Gait Posture, 36(3), 586-590. https://doi.org/10.1016/j.spinee.2013.03.027

Allard, P., Chavet, P., \& Barbier, F., et al. (2004). Effect of body morphology on standing balance in adolescent idiopathic scoliosis. American Journal of Physical Medicine\& Rehabilitation, 83, 689-697. 
https://doi.org/10.1097/01.PHM.0000137344.95784.15

Bennett, B. C., Abel, M. F., \& Granata, K. P. (2004). Seated postural control in adolescents with idiopathic scoliosis. Spine, 20, 449-454. https://doi.org/10.1097/01.brs.0000142005.21714.32

Bruyneel, A. V., Chavet, P., \& Bollini, G., et al. (2010). Idiopathic scoliosis and balance organisation in seated position on a seesaw. European Spine Journal, 19(5), 739-746. https://doi.org/10.1007/s00586-010-1325-x

Burwell, R. G., Aujla, R. K., \& Grevitt, M. P. et. al. (2012). Upper arm length model suggests transient bilateral asymmetry is associated with right thoracic adolescent idiopathic scoliosis (RT-AIS) with implications for pathogenesis and estimation of linear skeletal overgrowth. Stud Health Technol Inform, 176, 188-194. https://doi.org/10.3233/978-1-61499-067-3-188

Chamela - Bilińska, D., Zawadzka, D., \& Sobera, M., et al. (2005). Stabilność ciała w pozycji stojącej dzieci z bocznym idiopatycznym skrzywieniem kręgosłupa. Annales Universitatis Mariae Curie-Składowska, 16, 218-221.

Chen, Z., \& Lerman, J. (2012). Protection of the remaining spinal cord function with intraoperative neurophysiological monitoring during paraparetic scoliosis surgery: a case report. J Clin Monit Comput, 26(1), 13-16.

De Sèze, M., \& Cugy, E. (2012). Pathogenesis of idiopathic scoliosis: A review. Ann Phys Rehabil Med, 55(2), 128-138. https://doi.org/10.1016/j.rehab.2012.01.003

Eshraghi, E., Maroufi, N., \& Sanjari, M., et al. (2009). Static dynamic balance of schoolgirls with hyperkyphosis. Scolisis, 4(2), 05.

Głowacki, M., Kotwicki, T., \& Pucher, A. (2008). Skrzywienie kręgosłupa. In: W Marciniak \& A Szulc (Producer) Wiktora Degi Ortopedia i Rehabilitacja. Warszawa: PZWL.

Hosseinpour-Feizi, H., Soleimanpour, J., Sales, J. G., \& Arzroumchilar, A. (2011). Lenke and King classification systems for adolescent idiopathic scoliosis: interobserver agreement and postoperative results. Int $J$ Gen Med., 4, 821-825. https://doi.org/10.2147/IJGM.S25403

Janssen, M. M. A., \& De Wilde, R. F., et al. (2012). Experimental animal models in scoliosis research: a review of the literature, The Spine Journal, 4, 347-358. https://doi.org/10.1016/j.spinee.2011.03.010

Joo, S., Rogers, K. J., \& Donohoe, M. (2012). Prevalence and patterns of scoliosis in children with multiple pterygium syndrome. J Pediatr Orthop, 2, 190-195. https://doi.org/10.1097/BPO.0b013e31823ab359

Lee, R. S., Reed, D. W., \& Saifuddin, A. (2012). The correlation between coronal balance and neuroaxial abnormalities detected on MRI in adolescent idiopathic scoliosis. European Spine Journal, 4. https://doi.org/10.1007/s00586-012-2175-5

Ostrowska, B., Rożek-Piechura, K., \& Skolimowski, T. (2006). Odzyskiwanie dynamicznej równowagi po zewnętrznych zaburzeniach postawy $\mathrm{u}$ dzieci $\mathrm{z}$ idiopatyczną skoliozą. Ortopedia Traumatologia Rehabilitacja, 3, 300-307.

Shi, L., Wang, D., Chu, W. C., \& Burwell, G. R., et al. (2011). Automatic MRI segmentation and morphoanatomy analysis of the vestibular system in adolescent idiopathic scoliosis. NeuroImage, 54(1), 180-188. https://doi.org/10.1016/j.neuroimage.2010.04.002

Tao, F., Wang, Z., \& Li, M., et al. (2012). A comparison of anterior and posterior instrumentation for restoring and retaining sagittal balance in patients with idiopathic adolescent scoliosis. $J$ Spinal Disord Tech, 25(6), 303-308. https://doi.org/10.1097/BSD.0b013e3182204c3e

Weiss, H. (2012). Inclusion criteria for physical therapy intervention studies on scoliosis - a review of the literature. Stud Health Technol Inform, 176, 350-353.

Wilczyński, J., Habik, N., Bieniek, K., Janecka, S., Karolak, P., \& Wilczyński, I. (2018). Canonical correlations between body posture variables and postural stability in children with scoliosis and scoliotic posture. Modern Applied Science, 12(6), 58-69. https://doi.org/10.5539/mas.v12n6p58

\section{Notes}

Note 1. $\mathrm{n}$ - number of the tested; $\mathrm{x}$-mean; med - median, min -minimum value; max -maximum value; $\mathrm{r}$-gap; slant - slant; $\mathrm{k}$-curiosities. 
Note 2. In analysis of ariance the symbols mean: SS - sum of square, DF - degree of freedom, MS -mean of squares, F ratio of MS effectu to MS error, $\mathrm{p}$ - level of significance.

\section{Copyrights}

Copyright for this article is retained by the author(s), with first publication rights granted to the journal.

This is an open-access article distributed under the terms and conditions of the Creative Commons Attribution license (http://creativecommons.org/licenses/by/4.0/). 